\title{
URGENSI TUNTUTAN PROFESIONALISME DAN \\ HARAPAN MENJADI GURU BERKARAKTER \\ (Studi Kasus: Sekolah Dasar dan Sekolah Menengah Pertama di Kabupaten Batubara)
}

\author{
Deny Setiawan ${ }^{1}$ dan Joni Sitorus ${ }^{2}$ \\ ${ }^{1}$ Fakultas Ilmu Sosial Universitas Negeri Medan dan ${ }^{2}$ Balitbang Sumatera Utara \\ email: deny3setiawan@gmail.com
}

\begin{abstract}
Abstrak: Penelitian ini bertujuan untuk mendeskripsikan peningkatan profesionalisme guru, kualitas anak didik, dan guru yang berkarakter. Populasi penelitian adalah guru SD di Provinsi Sumatera Utara dengan sampel yang diambil secara purposive, yaitu Kabupaten Batubara. Pengumpulan data dilakukan dengan teknik tes, wawancara, FGD, dan studi dokumentasi. Analisis data dilakukan secara kualitatif dan kuantitatif dengan teknik statistik deskriptif. Hasil penelitian memperlihatkan bahwa nilai UKG SD dan SMP tahun 2013 di Kabupaten Batubara secara nasional sangat rendah, bahkan ada yang memiliki nilai kompetensi 1,0. Nilai rata-rata kompetensi guru hanya sebesar 39,61 untuk guru SD, masih berada di bawah nilai rata-rata secara nasional dan Provinsi Sumatera Utara. Nilai UKG SMP sebesar 46,86 masih berada di bawah nilai rata-rata nasional. Hal itu menunjukkan bahwa sebagian guru di Batubara masih memiliki profesionalisme yang rendah dalam melakukan tugas profesinya sehingga ke depan diharapkan perkembangan karakter guru yang berkualitas.
\end{abstract}

Kata Kunci: profesionalisme, guru karakter, kompetensi; kualitas

\section{THE URGENT DEMAND FOR PROFESSIONALISM AND THE HOPE FOR TEACHERS WITH GOOD CHARACTERS}

\begin{abstract}
The purpose of this research is to describe the improvement of teachers' professionalism, students' quality and teachers' characters. The research population was primary school teachers in North Sumatra in Batubara Regency who were recruited through purposive sampling. Data were collected through test, interview, FGD and documentation study. The research results show that the value of UKG at elementary and secondary schools in 2013 in Batubara Regency, is very low, and some schools even have the competence value as much as 1.0. The average of primary school teachers' competence is only 39.61, below the national and provincial average. While the SMP UKG value is 46.86 which is still below the national average. It shows that some teachers in Batubara are still less professional and thus need to further develop themselves to be qualified teachers.
\end{abstract}

Keywords: professionalism, teachers' characters, competency; quality

\section{PENDAHULUAN}

Kelayakan mengajar seorang guru jelas berhubungan erat dengan tingkat pendidikan guru dan juga watak atau karakter yang dimilikinya. Walaupun guru yang professional dan berkarakter bukan satu-satunya faktor penentu keberhasilan pendidikan, pengajaran ini merupakan titik sentral pendidikan dan kualifikasi sebagai cermin kualitas, dimana tenaga pengajar memberikan andil sangat besar pada kualitas pendidikan yang menjadi tanggung jawabnya. Profesi guru merupakan profesi tumpuan harapan banyak pihak guna mengatasi perubahan di masyarakat saat ini yang begitu cepat dan pesat. Kadang-kadang perubahan yang terjadi begitu cepat, tidak menyadarkan kita, bahwa hal itu telah mengubah banyak hal dalam sendi-sendi kehidupan di zaman modern ini.

Budimansyah (2007) menyatakan, terjadi perubahan pada masyarakat terutama dapat dilihat dari munculnya karakter buruk yang ditandai kondisi kehidupan sosial yang lambat-laun berubah. Pada zaman dahulu kita masih melihat budaya oaring Indonesia yang penyabar, ramah, penuh sopan santun, dan pandai berbasa-basi. Kini semua itu berubah menjadi pemarah, suka mencaci, pendendam, berbuat sadis, kejam, dan biadab.Oleh karena problematika yang membahayakan tersebut, di sini guru diharapkan mampu 
menanamkan kembali karakter bangsa yang sudah semakinberubah melalui pendidikan. Profesi guru menjadi harapan semua pihak, ketika perhatian pendidik informal sedang bergeser pada myopia politik sebagai sebuah lompatan.

Profesi berasal dari bahasa latin "proffesio" yang memunyai dua pengertian, yaitu janji/ ikrar dan pekerjaan. Bila artinya dibuat dalam pengertian yang lebih luas menjadi: kegiatan "apa saja" dan "siapa saja" untuk memperoleh nafkah yang dilakukan dengan suatu keahlian tertentu. Dalam arti sempit, profesi berarti kegiatan yang dijalankan berdasarkan keahlian dan dituntut pelaksanaan norma sosial dengan baik. Professionalisme adalah seorang guru, yang ahli dalam bidang keilmuan yang dikuasainya, dituntut bukan hanya sekadar mampu menstransfer keilmuan ke dalam diri anak didik, tetapi juga mampu mengembangkan potensi yang ada dalam diri peserta didik.

Kompetensi guru terdiri atas empat, yaitu kompetensi pedagogik, kompetensi kepribadian, kompetensi sosial, dan kompetensi profesional. Indikator keempat kompetensi ini berjumlah 24 kemampuan ideal seorang guru profesional. Kompetensi pedagogik terdapat 10 indikator; kompetensi kepribadian terdapat 5 indikator; kompetensi sosial terdiri atas 4 indikator; dan kompetensi profesional terdiri atas 5 indikator. Sagala (2000) menyatakan, pengertian profesionalisme adalah "komitmen untuk ide-ide profesional." Sejalan dengan itu, Hasan (2013) juga mengatakan, sikap profesional merupakan bagian dari profesionalisme.

Standardisasi guru dimulai dengan melakukan uji kompetensi awal. Tujuannya untuk seleksi awal guru yang layak ikut proses sertifikasi dan pemetaan (Antaranews.com).

Profesionalisme terdiri atas pengetahuan danpemahaman mengenai sikap terhadap profesi. Ketiganyadiperoleh melalui pendidikan profesi dan sikap profesional ini mulai terbentuk selama yang bersangkutan mengikuti pendidikan profesionalnya. Kualitas profesionalisme ditunjukkan dalam lima unjuk kerja sebagai berikut: (1) keinginan untuk selalu menampilkan perilaku yang mendekati standar ideal; (2) meningkatkan dan memelihara citra profesi; (3) keinginan untuk mengejar kesempatan pengembangan profesional yang dapat meningkatkan dan memperbaiki kualitas pengetahuan dan keterampilan; (4) mengejar kualitas dan cita-cita profesi; dan (5) memiliki kebanggaan terhadap profesinya.
Dalam Undang-undang Guru dan Dosen pasal 5 ayat (1) dikatakan bahwa profesi guru dan dosen merupakan bidang pekerjaaan khusus yang memerlukan prinsip-prinsip profesional, yaitu: (1) memiliki bakat, minat, panggilan jiwa dan idealisme; (2) memiliki kualifikasi pendidikan dan latar belakang pendidikan sesuai dengan bidang tugasnya; (3) memiliki kompetensi yang diperlukan sesuai dengan bidang tugasnya; (4) mematuhi kode etik profesi; (5) memiliki hak dan kewajiban dalam melaksanakan tugas; (6) memperoleh penghasilan yang ditentukan sesuai dengan prestasi kerjanya; (7) memiliki kesempatan untuk mengembangkan profesinya secara berkelanjutan; (8) memperoleh perlindungan hukum dalam melaksanakan tugas profesionalnya.

Oleh karena itu, pengakuan kedudukan guru dan dosen sebagai tenaga profesional dibuktikan dengan pemberian sertifikat pendidik. Seorang guru yang profesional disyaratkan wajib memiliki: (1) kualifikasi akademik Sarjana atau Diploma IV; (2) kompetensi pedagogik, kepribadian, sosial, dan profesional; (3) sertifikat pendidik; (4) sehat jasmani dan rohani; (5) kemampuan mewujudkan tujuan pendidikan nasional.

Undang-Undang Nomor 14 Tahun 2005 tentang Guru dan Dosen disebutkan bahwa guru adalah pendidik profesional dengan tugas utama mendidik, mengajar, membimbing, mengarahkan, melatih, menilai, dan mengevaluasi peserta didik pada pendidikan anak usia dini jalur pendidikan formal, pendidikan dasar, dan pendidikan menengah. Uno (2009:97) menyatakan bahwa guru adalah orang yang memiliki kemampuan merancang program pembelajaran serta mampu menata dan mengelola kelas agar peserta didik dapat belajar dan pada akhirnya dapat mencapai tingkat kedewasaan sebagai tujuan akhir dari proses pendidikan.

Di pihak lain, Aqib (Ungin, 2013:100) menyatakan bahwa "guru adalah sosok manusia yang harus digugu dan ditiru", dalam artian guru itu merupakan sosok yang seharusnya menjadi tauladan bagi peserta didik. Ada lima ukuran seorang guru itu dinyatakan profesional, yaitu memiliki komitmen pada siswa dan proses belajar, secara mendalam menguasai bahan ajaran dan cara mengajarnya, bertanggung jawab memantau kemampuan belajar siswa melalui berbagai teknik evaluasi, dan sebaiknya menjadi bagian dari masyarakat belajar pada lingkunganprofesinya. 
Mulyasa (2009:31) menyatakan, berbagai hal yang dilakukan guru dalam dunia pendidikan dapat diidentifikasi sedikitnya 19 peran guru, yaitu guru sebagai pendidik, pengajar, pembimbing, pelatih, penasihat, pembaharu (inovator), model dan teladan, pribadi, peneliti, pendorong kreativitas, pembangkit pandangan, pekerja rutin, pemindah kemah, pembawa cerita, aktor, emansipator, evaluator, pengawet, dan sebagai kulminator.

Kompetensi merupakan perilaku rasional untuk mencapai tujuan yang dipersyaratkan sesuai dengan kondisi yang diharapkan. Kompetensi merupakan peleburan dari pengetahuan, sikap, dan keterampilan yang diwujudkan dalam bentuk perbuatan. Dengan kata lain, kompetensi merupakan perpaduan dari penguasaan pengetahuan, keterampilan, nilai dan sikap yang direfleksikan dalam kebiasaan berpikir dan bertindak dalam melaksanakan tugas atau pekerjaannya.

Lickona (2001) menekankan tiga komponen karakter yang baik, yaitu moral knowing (pengetahuan tentang moral), moral feeling (perasaan tentang moral), dan moral action (perbuatan/tindakan moral), yang diperlukan agar anak mampu memahami, merasakan, dan mengerjakan nilai-nilai kebaikan pada gambar berikut.

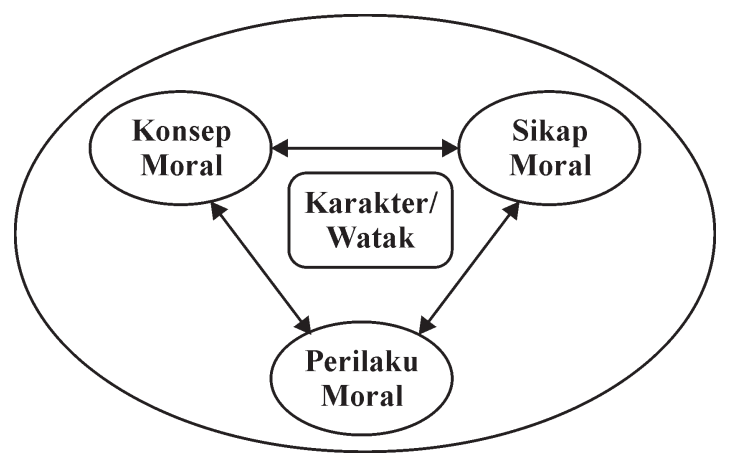

\section{Gambar 1. Teori Thomas Lickona Tentang 3 Komponen Karakter}

Pendidikan karakter di Indonesia didasarkan pada sembilan pilar karakter dasar. Karakter dasar menjadi tujuan pendidikan karakter. Kesembilan pilar karakter dasar ini, adalah (1) cinta kepada Allah dan semesta beserta isinya; (2) tanggung jawab, disiplin, dan mandiri; (3) jujur; (4) hormat dan santun; (5) kasih sayang, peduli, dan kerja sama; (6) percaya diri, kreatif, kerja keras, dan pantang menyerah; (7) keadilan dan kepemimpinan; (8) baik dan rendah hati; dan (9) toleransi, cinta damai, dan persatuan.
Sementara itu,Character Counts mengidentifkasikan bahwa karakter yang menjadi pilar adalah trustworthiness, respect, responsibility, fairness, caring, dan citizenship.

Mengingat guru adalah roh utama pendidikan, segenap karakter baik dan luhur harus dimilikinya. Meskipun di sisi lain guru tidak lebih dari manusia biasa yang bisa salah dan tidak lepas dari karakter-karakter buruk lainnya, sudah selayaknya karakter yang luhur dan mulia lebih dominan dimiliki dan lebih tampak dari pribadi seorang guru. Kemendiknas (2010) menunjukkan bahwa ada 18 nilai luhur yang harus dimiliki dan dipraktikkan terlebih dahulu oleh guru, baru kemudian diajarkan kepada anak didik dalam kehidupan nyata. Adapun ke-18 nilai luhur tersebut adalah religius, jujur, toleransi, disiplin, kerja keras, kreatif, mandiri, demokratis, rasa ingin tahu, semangat kebangsaan, cinta tanah air, menghargai prestasi, bersahabat/komunikatif, cinta damai, gemar membaca, peduli lingkungan, peduli sosial, tanggung jawab.

\section{METODE}

Penelitian ini merupakan penelitian kualitatif dengan pendekatan deskriptif, yaitu penelitian yang bersifat menggambarkan sebuah fenomena atas suatu peristiwa. Penelitian menggambarkan profil profesionalisme guru pada tingkat pendidikan dasar di Sumatera Utara. Jenis data meliputi data primer dan data sekunder. Data primer diperoleh melalui Focus Group Discussion (FGD) untuk mendapatkan makna dari suatu fenomena atau kejadian. Sedangkan data sekunder diperoleh melalui observasi dan studi dokumentasi.

Populasi penelitian adalah guru SD dan SMP di Kabupaten Batubara, Provinsi Sumatera Utara. Narasumber penelitian adalah Dinas Pendidikan, Badan Kepegawaian Daerah, Badan Perencanaan dan Pembangunan Daerah, kepala sekolah, dan guru. Sampel menggunakan purposive sampling, yaitu dengan memilih Kabupaten Batubara sebagai fokus penelitian. Dasar penentuan sampel ini didasarkan kepada Indeks Pembangunan Manusia (IPM) di Sumatera Utara sebagaimana dapat dilihat pada Tabel 1.

Pengumpulan data dilakukan untuk menjaring data primer dan skunder. Data primer diperoleh lewat tes untuk mengetahui kompetensi guru, wawancara, dan FGD, sedang data skunder lewat studi dokumentasi. Analisis data dilakukan secara kualitatif dan kuantitatif. Data wawancara, 
Tabel 1. Data Indeks Pembangunan Manusia Sumatera Utara

\begin{tabular}{|c|c|c|c|c|}
\hline No. & Nama Kabupaten/Kota & IPM & Sampel & Kategori \\
\hline 1. & Pematang Siantar & 77.9 & \multirow{8}{*}{ Pematangsiantar } & \multirow{8}{*}{ Tinggi } \\
\hline 2. & Medan & 77.8 & & \\
\hline 3. & Toba Samosir & 76.9 & & \\
\hline 4. & Tebing Tinggi & 76.9 & & \\
\hline 5. & Binjai & 76.9 & & \\
\hline 6. & Karo & 75.8 & & \\
\hline 7. & Deli Serdang & 75.8 & & \\
\hline 8. & Padangsidimpuan & 75.6 & & \\
\hline 9. & Sibolga & 75.5 & \multirow{8}{*}{ Tapanuli Utara } & \multirow{8}{*}{ Sedang } \\
\hline 10. & Tapanuli Utara & 74.9 & & \\
\hline 11. & Tanjung Balai & 74.7 & & \\
\hline 12. & Labuhan Batu & 74.7 & & \\
\hline 13. & Tapanuli Selatan & 74.5 & & \\
\hline 14. & Labuhan Batu Selatan & 74.4 & & \\
\hline 15. & Samosir & 74.3 & & \\
\hline 16. & Labuhan Batu Utara & 74.1 & & \\
\hline 17. & Simalungun & 73.9 & \multirow{8}{*}{ Dairi } & \multirow{8}{*}{ Kurang } \\
\hline 18. & Serdang Bedagai & 73.6 & & \\
\hline 19. & Langkat & 73.6 & & \\
\hline 20. & Dairi & 73.5 & & \\
\hline 21. & Padang Lawas Utara & 73.3 & & \\
\hline 22. & Asahan & 73.3 & & \\
\hline 23. & Padang Lawas & 72.6 & & \\
\hline 24. & Humbang Hasundutan & 72.4 & & \\
\hline 25. & Kota Gunungsitoli & 72.2 & \multirow{9}{*}{ Batubara } & \multirow{9}{*}{ Sangat Kurang } \\
\hline 26. & Batubara & 72.1 & & \\
\hline 27. & Tapanuli Tengah & 71.6 & & \\
\hline 28. & Pakpak Bharat & 71.2 & & \\
\hline 29. & Mandailing Natal & 71 & & \\
\hline 30. & Nias & 69.1 & & \\
\hline 31. & Nias Utara & 68.2 & & \\
\hline 32. & Nias Selatan & 67.7 & & \\
\hline 33. & Nias Barat & 67.1 & & \\
\hline
\end{tabular}

Sumber: Grand Design Kependudukan Sumatera Utara, 2013

FGD, dan dokumentasi dianalisis secara kualitatif, sedang hasil dianalisis dengan teknik statistik deskriptif.Untuk menghitung tingkat kompetensi guru, digunakan rumus:

$$
\mathrm{P}=\frac{f}{n} x 100
$$

$\mathrm{P}$ : Nilai kompetensi guru

f : Jumlah jawaban benar

$\mathrm{n}$ : Jumlah soal keseluruhan

Untuk menentukan tingkat kompetensi guru, dipergunakan kriteria yang ditunjukkan pada Tabel 2 . 
Tabel 3. Kriteria Kompetensi Profesionalisme Guru

\begin{tabular}{ccc}
\hline No. & Interval & Kategori \\
\hline 1 & $>85$ & Sangat tinggi \\
2 & $71-85$ & Tinggi \\
3 & $56-70$ & Sedang \\
4 & $41-55$ & Rendah \\
\hline \multicolumn{2}{l}{ Sumber: Syahrilfuddin, dkk (2011:82) }
\end{tabular}

HASIL DAN PEMBAHASAN

Profesionalisme Guru pada Tingkat SD dan SMP di Kabupaten Batubara

Data Kemdikbud tahun 2013 terkait hasil uji kompetensi guru (UKG) SDtahun 2013 di Kabupaten Batubara diperoleh ditunjukkan pada Gambar 2.

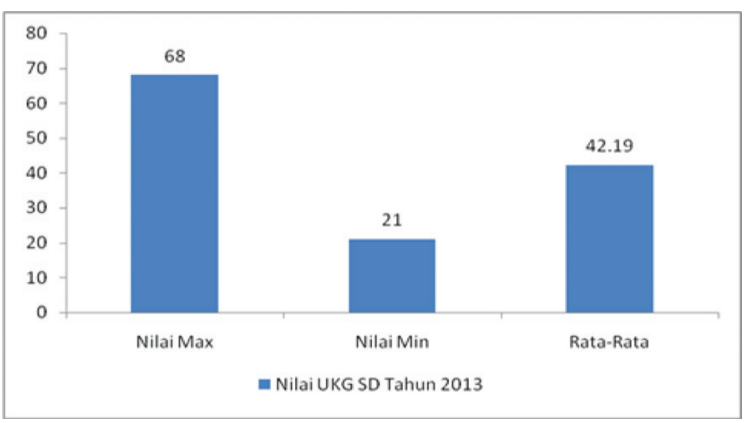

Gambar 2. Nilai UKG SD di Kabupaten Batubara Tahun 2013

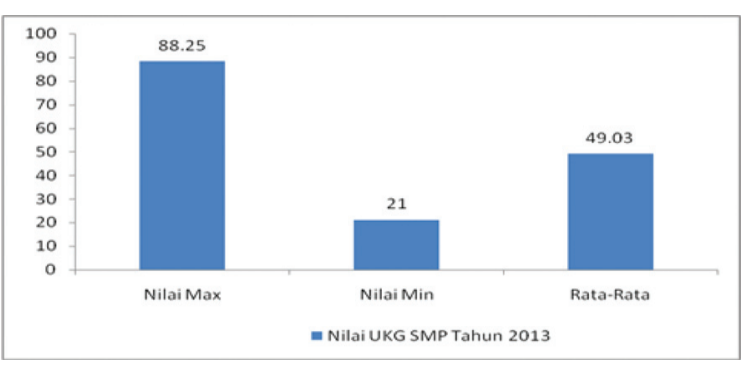

Gambar 3. Nilai UKG SMP di Kabupaten Batubara Tahun 2013

\section{Pembahasan}

Mencermati nilai UKG SD dan SMP tahun 2013 di Kabupaten Batubara berdasarkan hasil di atas jelas bahwa secara nasional guru-guru pada tingkat Pendidikan Dasar di Kabupaten Batubara memilki kompetensi yang sangat rendah, bahkan ada yang memilki nilai kompetensi 1,0 . Hal ini terbukti ketika diperoleh nilai rata-rata kompetensi guru tersebut hanya sebesar 39,61 untuk guru SD, masih berada di bawah nilai rata-rata secara nasional maupun tingkat Provinsi Sumatera Utara. Secara empirik hasil penelitian ini sejalan dengan hasil penelitian Rahmadani,dkk (2016:163).

Nilai UKG SMP sebesar 46,86 masih berada di bawah nilai rata-rata secara nasional, namun telah berada di atas nilai rata-rata UKG di Provinsi Sumatera Utara. Rentang nilai UKG pada tingkat Pendidikan Dasar tahun 2013 di Kabupaten Batubara sangat tinggi, khususnya rentang nilai UKG SMP. Misalnya, hasil UKG SD, nilai tertinggi sebesar 70 dan terendah 10 sehingga diperoleh rentang nilai sebesar 60 .

Selanjutnya, hasil UKG SMP memiliki nilai tertinggi sebesar 80,75 dan terendah sebesar 1,0, sehingga diperoleh rentang nilai sebesar 79,75. Hal itu berarti bahwa tingkat kompetensi pedagogik dan profesional guru, baik guru SD maupun SMP memiliki sebaran yang sangat beragam. Berdasarkan sebaran tingkat kompetensi guru di tingkat Pendidikan Dasar di Kabupaten Batubara tersebut di atas, maka langkah awal yang seharusnya dilakukan oleh pemerintah adalah melakukan identifikasi tingkat kompetensi guru untuk pemetaan, namun pemerintah daerah dinilai kurang peduli.

Khusus guru SMP, Pemerintah Kabupaten Batubara tidak cukup hanya melakukan pemetaan, namun juga perlu melakukan wawancara mendalam terhadap sejumlah guru yang memiliki nilai yang sangat rendah tersebut, yaitu hanya 1,0 . Berdasarkan hasil wawan-cara tersebut nantinya diperoleh informasi faktor apa yang menyebabkan rendahnya nilai kompetensi guru yang bersangkutan. Hasil peta tingkat kompetensi guru tersebut nantinya akan dijadikan sebagai dasar kebijakan pemerintah untuk mengadakan pendidikan dan pelatihan guru berdasarkan tingkat kompetensi guru yang dimiliki.

Guru yang memiliki kompetensi tingkat rendah, maka diberikan pendidikan dan pelatihan tingkat dasar, atau sebaliknya guru yang memilki kompetensi tingkat sedang atau tinggi, maka diberikan pendidikan dan pelatihan tingkat lanjutan. Khusus sejumlah guru SMP yang memiliki nilai kompetensi sebesar 1,0, tidak cukup hanya memberikan pendidikan d an pelatihan berdasarkan tingkat kompetensinya, namun juga perlu memperhitungkan cara, metode, dan strategi penyampaian materi pada kegiatan pendidikan dan pelatihan guru dimaksud. Hal ini sejalan dengan penelitian Saragih (2013:7) yang mengungkapkan bahwa guru harus memahami cara, metode, dan trategi penyampaian materi. 
Hal itu membawa konsekuensi bahwa Pemerintah Kabupaten Batubara perlu menginformasikan kepada sejumlah widyasuara/instruktur/ narasumber pendidikan dan pelati-han guru untuk memberikan treatment khusus bagi guru-guru yang dimaksud. Pemerintah dituntut memberikan perubahan pelaksanaan pendidikan dan pelatihan guru yang selama ini dalam implementasinya tidak tepat sasaran. Selanjutnya, bila dilihat dari sebaran nilai kompetensi guru seperti pada Gambar 4.7 dan 4.8 di atas tersebut, bahwa perbandingan nilai kompetensi guru SMP terendah lebih rendah daripada nilai kompetensi guru SD terendah. Artinya, peningkatan kompetensi guru melalui pendidikan dan pelatihan yang dilakukan oleh Pemerintah Kabupaten Batubara melalui Dinas Pendidikan harus lebih memprioritaskan guru SMP, dengan tidak mengabaikan guru SD. Guru SMP yang memilki nilai kompetensi terendah tersebut sangat tidak layak untuk mengajar, terlebih-lebih untuk sebutan guru yang profesional.

Sementara itu, para guru yang memiliki nilai kompetensi rendah tersebut telah lulus sertifikasi dan memperoleh sertifikat pendidik. Sertifikat pendidik yang diperoleh guru tersebut dijadikan sebagai salah satu syarat seorang guru profesional. Namun, sebutan guru yang profesional tersebut dalam kenyataanya tidak sesuai dengan nilai kompetensi yang dimiliki, lebih khususnya terhadap tindakan guru dalam implementasinya. Terlepas hasil temuan bahwa masih ada guru SMP di Kabupaten Batubara yang memilki nilai kompetensi hanya sebesar 1,0, namun peneliti menganggap ini hanya seorang oknum, artinya hanya beberapa orang guru saja.

Dari hasil di atas bisa dikatakan bahwa guru-guru di Kabupaten Batubara belum bisa dikategorikan sebagai guru yang berkarakter yang sangat dibutuhkan oleh murid-murid. Guru di Batubara belum mencintai muridnya dengan sepenuh hati dalam memberikan materi pelajaran. Ini sesuai dengan apa yang dikatakan oleh Apriani (2016) bahwa guru yang berkarakter harus memberikan materi pelajaran dengan sepenuh hati.

Dalam pembentukan guru yang berkarakter di Kabupaten Batubara, perlu juga menanamkan nilai-nilai agama dan nilai-nilai kebangsaan kepada guru-guru tersebut. Ini juga sesuai dengan pernyataan Samsuri dan Marzuki (2016:27) yang mengatakan bahwa nilai-nilai agama dan kebangsaan akan membentuk nilai karakter.
Guru harus dapat menempatkan diri sebagai orang tua kedua dengan mengemban tugas yang dipercayakan orang tua kandung/wali dalam jangka waktu tertentu. Oleh karena itu, pemahaman terhadap jiwa dan watak anak didik diperlukan agar dapat dengan mudah memahami jiwa dan watak anak didik (Djamarah. 2000).

Guru bisa dikatakan sebagai pemimpin di dalam kelas. Seorang pemimpin harus memiliki moral yang baik. Ini juga sejalan dengan pernyataan Bass dan Steidlmeier (1999) bahwa seorang pemimpin harus memiliki karakter moral yang baik. Seorang pemimpin, di samping punya karakter moral yang bagus, juga harus memiliki etika. Ini juga yang disampaikan oleh Avolio, et al. (2005) bahwa seorang pemimpin harus memiliki etika yang bisa jadi panutan bagi murid-muridnya atau bawahannya.

Faktor-faktor penghambat peningkatan profesionalisme guru di tingkat Pendidikan Dasar di Sumatera Utara, khususnya Kabupaten Batubara adalah sebagai berikut.

a. Regulasi terhadap pengawas belum diatur secara mengikat; regulasi terhadap pendidikan dan pelatihan, mulai dari perencanaan, pelaksanaan, dan evaluasi juga belum dituangkan dalam suatu rencana kerja; serta regulasi pemberian reward dan punishment guru belum diatur.

b. Kegiatan-kegiatan sekolah untuk meningkatkan profesionalisme guru, mulai workshop, mengikuti seminar, diskusi ilmiah, inhouse traning melalui KKG/MGMP, ataupun kegiatan lainnya belum tersistem ataupun terprogram pada program dan kegiatan di Dinas Pendidikan. Kegiatan-kegiatan tersebut hanya dilakukan pada momen-momen tertentu saja dan tidak berkelanjutan.

c. Peningkatan kompetensi guru di daerah masih difokuskan pada 2 (dua) kompetensi, yaitu profesional dan pedagogik guru, sementara untuk 2 (dua) kompetensi guru lainnya, kepribadian dan sosial guru belum menjadi prioritas Dinas Pendidikan di daerah.

d. Reward dan punishment bagi guru belum menjadi fokus perhatian penting oleh Dinas Pendidikan, sehingga berdampak pada motivasi dan kinerja guru sebagai pendidik dan pengajar yang profesional.

Banyak faktor yang menyebabkan rendahnya kualitas guru. Salah satunya kesejahteraan guru yang kurang diperhatikan. Ini juga yang 
diungkapkan Baswedan (Kompas.com), salah satu penyebab rendahnya kualitas guru adalah kesejahteraan guru tidak memadai.

\section{KESIMPULAN}

Hasil penelitian terlihat bahwa nilai UKG SD dan SMP tahun 2013 di Kabupaten Batubara, secara nasional sangat rendah, bahkan ada yang memilki nilai kompetensi 1,0 . Hal ini terbukti ketika diperoleh nilai rata-rata kompetensi guru tersebut hanya sebesar 39,61 untuk guru SD, masih berada di bawah nilai rata-rata secara nasional maupun tingkat Provinsi Sumatera Utara. Nilai UKG SMP sebesar 46,86 masih berada di bawah nilai rata-rata secara nasional.Hal itu menunjukkan bahwa sebagian guru di Batubara masih memiliki profesionalisme yang rendah dalam melakukan tugas profesinya sehingga ke depan diharapkan perkembangan karakter guru yang berkualitas.

\section{UCAPAN TERIMAKASIH}

Ucapan terimakasih disampaikan kepada Balitbang Sumut yang telah memberikan kesempatan kepada penulis dalam melakukan penelitian ini. Ucapan terimakasih juga disampaikan kepada Ketua Dewan Redaksi Cakrawala Pendidikan yakni Prof. Dr. Burhan Nurgiantoro yang telah memberikan banyak masukan terhadap perbaikan artikel ini.

\section{DAFTAR PUSTAKA}

Antaranews. 2013. Kemendikbud Akui Kualitas Guru Masih Rendah,berita hari Jumat, 5 September 2013, http://www.antaranews. com/berita/397722/kemdikbud-akuikualitas guru-masih-rendah. Diakses pada 5 April 2015.

Apriani, An-Nisa. 2016. Guru Berkarakter: Gurunya Manusia. Online:http//almaata.ac.id/ guru-berkarakter-gurunya-manusia/(1).

Avolio, Bruce J. Dan William L. Gardner. 2005. "Authentic leadershipdevelopment: Getting to the root of positive forms of leadership" dalam The Leadership Quarterly, Volume 16, Issue 3, Pages 315-338.Elsevier Science Inc.

Bass, Bernard M dan Paul Steidlmeier. 1999. "Ethics, character, and authentic transfor- mational leadership behavior", dalam The Leadership Quarterly, Volume 10, Issue 2, Pages 181-217. Elsevier Science Inc.

Baswedan, Anies. 2013. VIP-kan Guru-guru Kita! Artikel (online) (http://edukasi. kompas.eom/read/2013/1 1/28/1100170/ VIP-kan.Guru-guru.Kita. diakses pada 5 April 2015).

Budimansyah, Dasim. 2007. "Pendidikan Demokrasi Sebagai Konteks Civic Education di Negara Berkembang," in Acta Civicus, Jurnal Pendidikan Kewarganegaraan, Vol 1, No 1, 2007, hal 11-26.

Djamarah, Syaiful Bahri. 2000. Guru dan Anak Didik dalam Interaksi Edukatif. Jakarta: Rineka Cipta.

Hasan, Hamid. 2013. Informasi Kurikulum 2013. Bandung: Universitas Pendidikan Indonesia.

Kementerian Pendidikan Nasional, 2010, Pengembangan Pendidikan Budaya dan Karakter Bangsa-Pedoman Sekolah, Jakarta: Badan Penelitian dan Pengembangan.

Lickona, Thomas. 2001. Educating for Character: How Our Schools Can Teach Respect and Responsibility, New York: Bantam Books.

Mulyasa, E. 2009. Standar Kompetensidan Sertifikasi Guru. Bandung: Remaja Rosdakarya.

Rahmadani, Fitri, Harahap, F, dan Edi. S. 2016. "Analisis Kompetensi Guru Biologi SMA Se-Kabupaten Batu Bara", in Jurnal Pendidikan Biologi, Vol 5, No 3, hal 160166.

Sagala, Syaiful. 2000. Pengembangan dan Implementasi Kurikulum Penting Untuk Meningkatkan Kualitas Pembelajaran. http:// disilib.unimed.ac.id/vublic/ UNIMED-Article28973Pensembansan\%20Kurikulum. pdf. (diakses Maret 2015). 
Saragih, Marintan Deborah.2013. "Hubungan Antara Kompetensi Dengan Kinerja Mengajar Guru SD Kecamatan Medan Deras, Kabupten Batubara". In Jurnal Tabularasa PPS Unimed Vol 10, No 1, hal 01-12.

Sistem Pendidikan Nasional (Sikdisnas). 2012. Keberhasilan Kurikulum 2013. http://www. kemdiknas.go.id/kedikbud/un-vublik-kurikulum-2013-5 Diakses Maret 2015.

Syahrilfuddin. dkk. 2011. Penelitian Tindakan Kelas. Cendikia Insani: Pekanbaru.

Undang-undang Republik Indonesia No 14 Tahun 2005 tentang Guru dan Dosen.
Ungin, Maria. 2013. "Studi tentang Kualitas Tenaga Pengajar (Guru) pada SMPN 17 Sendawar Kabupaten Kutai Barat." dalam Jurnal Administrasi Negara. 1 (1). Hlm. 97-108.99. Profesi Keguruan. Jakarta: Rineka Cipta.

http://taufikrizaldi.blogs.uny.ac.id/201/12/21/ profesionalisasi-guru-dan-pendidikankarakter/http://profdikguru.blogspot. co.id/2015/05/guru-yang-berkarakter. htmlWikipedia.

Uno, H.B.2009. Profesi Kependidikan: Problema, Solusi, dan Reformasi Pendidikan di Indonesia. Jakarta: Bumi Aksara. 